\title{
Gradhiva
}

GRADHIV

Revue d'anthropologie et d'histoire des arts

$7 \mid 2008$

Le possédé spectaculaire

\section{Jacques Hainard et Philippe Mathez (dir.), Le Vodou, un art de vivre}

photographies de Johnathan Watts.Gollion, Infolio éditions-Genève, musée d'Ethnographie, 2007, 176 p.

\section{Bertrand Hell}

\section{OpenEdition}

Journals

Édition électronique

URL : http://journals.openedition.org/gradhiva/1156

DOI : $10.4000 /$ gradhiva. 1156

ISSN : $1760-849 X$

Éditeur

Musée du quai Branly Jacques Chirac

Édition imprimée

Date de publication : 15 mai 2008

Pagination : 171

ISBN : 978-2-915133-86-8

ISSN : 0764-8928

Référence électronique

Bertrand Hell, « Jacques Hainard et Philippe Mathez (dir.), Le Vodou, un art de vivre », Gradhiva [En ligne], 7| 2008, mis en ligne le 03 décembre 2010, consulté le 19 avril 2019. URL : http://

journals.openedition.org/gradhiva/1156; DOI : 10.4000/gradhiva.1156

Ce document a été généré automatiquement le 19 avril 2019.

(C) musée du quai Branly 


\section{Jacques Hainard et Philippe Mathez (dir.), Le Vodou, un art de vivre}

photographies de Johnathan Watts.Gollion, Infolio éditions-Genève, musée d'Ethnographie, 2007, 176 p.

\section{Bertrand Hell}

\section{RÉFÉRENCE}

Jacques Hainard et Philippe Mathez (dir.), Le Vodou, un art de vivre, photographies de Johnathan Watts. Gollion, Infolio éditions-Genève, musée d'Ethnographie, 2007, 176 p.

1 Une réelle force d'envoûtement. Tel est bien ce que dégage cet extraordinaire catalogue édité par le musée d'Ethnographie de Genève à l'occasion de la présentation de l'exposition sur le vodou haïtien ${ }^{1}$ (décembre 2007-31 août 2008). Le choix de cette expression n'est pas simple figure rhétorique, il reflète aussi la trame narrative choisie par les concepteurs de cette exposition, à savoir s'inspirer du poème de Charles Baudelaire Le Flacon. Les multiples flacons et contenants rituels sont là " pour dire à la fois l'essai, la volonté et le désir de maîtriser, tout en rappelant l'immensité et la vacuité de la tâche » (p. 15). L'essence du vodou, comme le parfum, garde toujours un caractère insaisissable. Reproduisant fidèlement le parcours muséographique, le catalogue nous fait pénétrer à travers dix chapitres ( «boite noire », « pandore ", « vitrifié », etc.) au cœur de l'étonnante collection d'objets vodou réunie par Marianne Lehmann, une Suissesse installée en Haïti depuis 1957. Miroirs lourdement décorés, autels du culte rada, statuettes de lwa ou encore fauteuil de traitement garni de bouteilles : bien sûr, tous ces objets rituels recèlent une puissance esthétique propre à fasciner. Mais la force d'envoûtement de ce catalogue réside aussi dans le remarquable travail de mise en scène opéré par le photographe Johnathan Watts, compagnon de route du musée depuis 1993 et auteur de multiples publications (dont Kerala : des dieux et des hommes, en 2004). Ainsi pour le chapitre IX, « Motus », consacré aux figurines bizango (p. 128-157), il a choisi le contre- 
jour, l'ombre, le fond sombre et pourpre pour rendre plus prégnant le mystère entourant les rituels de cette société secrète liée à la nuit, à la guerre et à la mort.

Plusieurs textes accompagnent notre incursion dans le monde vodou: quelques vignettes ethnographiques tirées d'ouvrages anthropologiques, un rappel de l'importance des traditions plastiques vodou-mayaka dans le patrimoine haïtien (p. 167-172) et une interview de Marianne Lehmann qui évoque les conditions dans lesquelles son exceptionnelle collection de trois mille pièces - essentiellement liée au «vodou de la nuit » - a pu être réunie (p. 19-23). Mais le lecteur trouvera également un entretien avec Max Beauvoir, un houngan de Port-au-Prince dont le point de vue est particulièrement intéressant. Petit-fils de l'un des plus grands houngan d'Haïti qui l'adouba sur son lit de mort, initié, chef du péristyle de Mariani, un sanctuaire connu internationalement depuis 1974, Beauvoir est aussi un ingénieur biochimiste de formation, ayant exercé un métier de chercheur aux États-Unis et en France, et un intellectuel engagé. Outre ses tâches quotidiennes de houngan, il s'investit actuellement dans un travail de préservation du vodou haïtien (en publiant et en traduisant des chants rituels notamment), une « construction unique » dont il souligne la profonde originalité au sein du complexe des religions liées à la traite des Noirs. Son combat - tant politique que patrimonial - s'appuie sur une profonde réflexion, fruit de sa trajectoire singulière (p. 25-33).

3 Ce catalogue est à tout point de vue remarquable. Il porte incontestablement la marque de Jacques Hainard, directeur du musée d'Ethnographie de Genève depuis 2006. On y retrouve son minutieux souci du détail, mais aussi ce regard anthropologique si particulier qui présida à ses années neuchâteloises : une partialité (inspirée par Michel Leiris) postulant que « seul le cumul de subjectivités est à même d'assurer l'objectivité ${ }^{2}$ " (p. 14).

\section{NOTES}

1. Après sa première mondiale à Genève, cette exposition sera présentée au Tropenmuseum d'Amsterdam et à l'Übersee-Museum de Brême.

2. Cette volonté de cumuler les subjectivités inspire également le recueil de contributions publié parallèlement à ce catalogue. Une vingtaine d'auteurs illustrent la multiplicité des facettes d'un phénomène ne se laissant pas enfermer dans les catégories classiques de «culture " ou de « religion» (Vodou, J. Hainard, Ph. Mathez et O. Schinz (dir.). Gollion, Infolio Éditions-Genève, musée d'Ethnographie (« Tabou »), 2008, 444 p.). 


\section{AUTEURS}

BERTRAND HELL

bhell@wanadoo.fr 